\title{
Positive and Negative Affectivity and Their Relation to Anxiety and Depressive Disorders
}

\author{
David Watson and Lee Anna Clark \\ Southern Methodist University \\ Greg Carey \\ Institute for Behavioral Genetics, University of Colorado
}

\begin{abstract}
Distinguishing between depression and anxiety has been a matter of concern and controversy for some time. Studies in normal samples have suggested, however, that assessment of two broad mood factors--Negative Affect (NA) and Positive Affect (PA)-may improve their differentiation. The present study extends these findings to a clinical sample. As part of an ongoing twin study, 90 inpatient probands and 60 cotwins were interviewed with the anxiety and depression sections of the Diagnostic Interview Schedule (DIS; Robins, Helzer, Croughan, \& Ratcliff, 1981). Respondents also completed trait NA and PA scales. Consistent with previous research, NA was broadly correlated with symptoms and diagnoses of both anxiety and depression, and acted as a general predictor of psychiatric disorder. In contrast, PA was consistently related (negatively) only to symptoms and diagnoses of depression, indicating that the loss of pleasurable engagement is a distinctive feature of depression. The results suggest that strengthening the PA component in depression measures may enhance their discriminative power.
\end{abstract}

Clinicians have long been concerned by the conceptual and empirical overlap between anxiety and depression, and have recently devoted considerable attention to their differentiation (e.g., Akiskal, 1985; Breier, Charney, \& Heninger, 1985). Although the association is strong enough to suggest to some researchers that they are variants of a single disorder, most clinicians and researchers in the area continue to believe that the basic distinction is valid (e.g., Akiskal, 1985; Foa \& Foa, 1982). A complete discussion of this literature is beyond the scope of our article, but we will present evidence illustrating the magnitude of the problem.

Numerous studies have demonstrated that self-report anxiety and depression scales are highly correlated, typically in the range of .40 to .70 . This finding is, moreover, both robust and general: Such correlations have been reported in college students (Dobson, 1985; Gotlib, 1984; Nezu, Nezu, \& Nezu, 1986; Tanaka-Matsumi \& Kameoka, 1986), children (Blumberg \& Izard, 1986; Wolfe et al., 1987), normal adults (Orme, Reis, \& Herz, 1986), and diverse patient samples (Bouman \& Luteijn, 1986; Mendels, Weinstein, \& Cochrane, 1972; Zurawski \& Smith, 1987). The correlations are often high enough to suggest that they tap a single construct. In fact, different measures of anxiety and depression are as highly correlated with each other

This research was supported in part by National Institute of Mental Health Grant MH14677.

We are deeply indebted to Irving I. Gottesman, Codirector of the Washington University Twin Series, for his help in securing the data used in this study.

Correspondence concerning this article should be addressed to David Watson, Department of Psychology, Southern Methodist University, Dallas, Texas 75275 . as they are among themselves, and thus often load on a single, undifferentiated factor, together with measures of hostility and anger, neuroticism, physical complaints, repression-sensitization, irrational beliefs, and (on the opposite pole) with ego strength and social desirability (e.g., Dobson, 1985; Gotlib, 1984; Mendels et al., 1972; Tanaka-Matsumi \& Kameoka, 1986). Many investigators have concluded that all of these measures tap a common, underlying construct of Negative Affectivity, Neuroticism, or General Psychological Distress (Eysenck, 1970; Gotlib, 1984; Watson \& Clark, 1984; Zurawski \& Smith, 1987).

These findings obviously cause interpretive problems for research involving self-report scales and suggest that they offer little help in differential diagnosis. Indeed, "anxiety" scales have been found to correlate as highly with clinical ratings of depression as they do with anxiety; and conversely, "depression" scales are as strongly correlated with clinically rated anxiety as depression (e.g., Deluty, Deluty, \& Carver, 1986; Zuckerman, Persky, Eckman, \& Hopkins, 1967). It would be a mistake, however, to conclude that these data simply reflect the limitations of self-report. Clinicians' and teachers' ratings of anxiety and depression are also strongly correlated (Deluty et al., 1986; Foa et al., 1983; Lipman, Rickels, Covi, Derogatis, \& Uhlenhuth, 1969; Wolfe et al., 1987; Zuckerman et al., 1967), anxious and depressive symptoms co-occur in many patients (Derogatis, Klerman, \& Lipman, 1972; Roth, Gurney, Garside, \& Kerr, 1972), and comorbidity of the full clinical syndromes occurs in about half of all patients with anxiety or depressive diagnoses (e.g., Breier, Charney, \& Heninger, 1986; Woodruff, Guze, \& Clayton, 1972; for reviews, see Breier et al., 1985; Clark, in press; Gersh \& Fowles, 1979).

Taken together, these data demonstrate a substantial degree 
of overlap between anxiety and depression, regardless of the level considered. However, the data by no means imply that a distinction between anxiety and depression cannot be made. Correlations in the .40 to .70 range leave much variance unaccounted for, and half of all patients with anxiety or depressive disorders show relatively pure syndromes. Furthermore, one can point to distinct subgroups of patients within each class, and to subjective and physiological correlates that are unique to each type of disorder (e.g., the disturbance of rapid eye movement [REM] sleep in depression, but not anxiety; see Akiskal, 1985; Kupfer et al., 1983). Even proponents of differentiability, however, recognize the aforementioned problems, and agree on the need for further research to identify factors that will improve their distinction.

In this article we will report on one such factor. Specifically, we will relate symptoms and diagnoses of anxiety and depression to two general mood-based personality factors, Positive Affectivity and Negative Affectivity. We will show that Positive Affectivity-but not Negative Affectivity-can be clinically useful in distinguishing these two classes of disorder.

\section{Positive and Negative Affect}

Extensive evidence demonstrates that two broad mood factors-Positive Affect and Negative Affect-are the dominant dimensions in self-reported mood (Watson, Clark, \& Tellegen, 1984; Watson \& Tellegen, 1985). Although their names might suggest that they are opposite poles of the same dimension, Positive and Negative Affect are in fact highly distinctive dimensions that can be meaningfully represented as orthogonal (uncorrelated) factors. Both mood factors can be measured either as a state (i.e., transient fluctuations in mood) or as a trait (i.e., stable individual differences in general affective tone). Our article will focus on the traits, which Tellegen (1982) has termed Negative Affectivity (NA) and Positive Affectivity (PA).

Negative Affect is a general factor of subjective distress, and subsumes a broad range of negative mood states, including fear, anxiety, hostility, scorn, and disgust. Mood states related to depression such as sadness and loneliness also have substantial loadings on this factor. At the trait level, NA is a broad and pervasive predisposition to experience negative emotions that has further influences on cognition, self-concept, and world view (Watson \& Clark, 1984). In contrast, PA is a dimension reflecting one's level of pleasurable engagement with the environment. High PA is composed of terms reflecting one's enthusiasm, energy level, mental alertness, interest, joy, and determination, whereas low PA is best defined by descriptors reflecting lethargy and fatigue. It is noteworthy that states of sadness and loneliness also have relatively strong loadings on the low end of this factor (Watson \& Tellegen, 1985). Trait PA is a corresponding predisposition conducive to positive emotional experience; it reflects a generalized sense of well-being and competence, and of effective interpersonal engagement.

Putting these data together, we have the following pattern: Anxiety is essentially a state of high NA, and has no significant relation with $\mathrm{PA}$, but depression is a mixed state of high NA and low PA. Tellegen (1985) specifically tested this model by factor analyzing measures of anxiety, depression, NA, and PA. The results were generally consistent with the model. As ex- pected, the NA and PA scales each defined a factor. The anxiety and depression scales had significant loadings on both factors; however, the anxiety scale loaded more strongly on the NA factor, whereas the depression scale was a much better marker of low PA. Similarly, Blumberg and Izard (1986) used self-report mood scales to predict scores on measures of depression and anxiety. Several of the negative emotion scales (most notably Sadness and Fear) contributed to the prediction of both measures, but the positive emotion scales (Joy and Interest) added significantly only to the prediction of depression. The mood data therefore suggest that PA may be an important factor in differentiating anxiety from depression (Tellegen, 1985; Watson \& Tellegen, 1985).

These studies, however, were conducted with normal subjects and did not involve trait measures. Two studies have reported supportive results using clinical samples. First, Hall (1977) obtained diagnostic data and clinicians'ratings of anxiety and depression on a sample of 108 male outpatients. She found ratings and diagnoses of anxiety to be significantly correlated with NA, but not PA, whereas ratings and diagnoses of depression were more highly related to (low) PA than NA. Second, Bouman and Luteijn (1986) examined three groups of patients: (a) major depressives, (b) dysthymics, and (c) nondepressives. Scores on a number of mood and personality scales were factor analyzed, and two factors were extracted and interpreted as NA and PA. Consistent with the model outlined earlier, the major depressives had significantly lower PA scores than the dysphoric patients, who were, in turn, lower on PA than the nondepressed group. The latter data do not permit any comparison between anxiety and depression, however.

Our study provides the most comprehensive test of the model to date. We examined the relation of trait PA and NA scores to symptoms and diagnoses of depression and anxiety in a clinical patient population. On the basis of the data we have reviewed, we predicted that NA scores would be significantly correlated with both anxiety and depression, whereas PA scores would be associated only with the latter.

\section{Method}

\section{Subjects}

Subjects were twins and their cotwins contacted as part of the Washington University Twin Series, a large-scale study of the heritability of psychiatric disorders. Most (90\%) of the proband twins were admitted to in- and outpatient psychiatric units staffed by personnel from the Washington University School of Medicine Department of Psychiatry; an additional $10 \%$ were ascertained through private treatment facilities for substance abuse not affiliated with Washington Univensity. Cooperating probands and their cotwins were administered a battery of interviews, and were then given several self-report measures to complete. In many cases these were returned by mail, and on the average were completed within 3 weeks of the interview. All probands $(n=90)$ who completed both the interviews and self-report measures by July 1984 were included in our analyses. Of the cotwins, we included only those $(n=60)$ who also received either a computer-generated Diagnostic Interview Schedule diagnosis for an anxiety or depressive disorder, or a Diagnostic and Statistical Manual of Mental Disorders (3rd edition; DSM-III; American Psychiatric Association, 1980) diagnosis for any disorder by a consensus of the research staff. Thus, the final sample 
consisted of 150 patients with a mean age of $46.6(S D=13.1)$. Of these, $84(56 \%)$ were female.

\section{Measures}

Trait NA and PA scales. Trait NA and PA were assessed using scales from the Multidimensional Personality Questionnaire (MPQ; Tellegen, in press, formerly called the Differential Personality Questionnaire), a 300-item general true-false inventory designed to measure normalrange personality. For Trait NA, we used the 14-item Negative Emotionality (NEM) Scale, which is particularly well-suited for our purposes in that it focuses specifically on the experience of negative affect and does not directly assess psychiatric problems and complaints. Thus, its correlations with psychiatric symptoms and diagnoses do not simply reflect content overlap. High NEM scorers describe themselves as nervous, worrying, irritable, overly sensitive, and emotionally labile. For example, high NEM scorers report that they often are irritated by small annoyances, and that their feelings are easily hurt. NEM is internally consistent (coefficient alpha $=.82, n=872$ ) and stable over time (12-week retest $r=.72, n=109$; Watson \& Pennebaker, in press). The mean NEM score in this sample was $8.2(S D=4.3)$, significantly higher than that found in a normal adult sample $(M=6.5, S D=3.8), t(311)=3.6, p<$ .01 (Watson \& Pennebaker, 1988).

Trait PA was assessed by using the 11-item Positive Emotionality (PEM) Scale. High PEM scorers describe themselves as happy and enthusiastic, as having a lot of energy, and as leading an interesting and exciting life. For example, high PEM scorers report that they often feel happy and content for no special reason, and that they do some fun things nearly every day. PEM is also homogeneous (coefficient alpha = .80 ) and stable (12-week retest $r=.77$; Watson \& Pennebaker, in press). The mean PEM score in this sample was $6.5(S D=3.2)$, significantly lower than that reported for normal adults $(M=8.4, S D=2.5)$, $t(311)=5.7, p<.01$ (Watson \& Pennebaker, 1988).

Across several samples, we have found NEM and PEM to be reasonably independent of one another, with an average correlation of approximately - 30 (Watson, 1988; Watson \& Pennebaker, in press). In the current sample they have a correlation of -.37 . NEM and PEM also show good convergent and discriminant validity when related to mood scales and other variables (e.g., Watson, 1988; Watson \& Pennebaker, in press).

Diagnostic interview schedule. The interview schedule used for the assessment of anxiety and depression was based on Version 3.0 of the Diagnostic Interview Schedule (DIS; Robins, Helzer, Croughan, \& Ratcliff, 1981) and was administered by trained psychiatrists, psychologists, or research technicians. Although we do not have data regarding the reliability of the DIS with these raters, the interview itself has been shown to be highly reliable (Hesselbrock, Stabenau, Hesselbrock, Mirkin, \& Meyer, 1982). As for its validity, the results have been mixed, but studies have generally supported its use as a diagnostic measure, even with lay interviewers (Anthony et al., 1985; Helzer et al., 1985; Robins et al., 1981; Wittchen, Semler, \& von Zerssen, 1985. For a general discussion of the DIS as a diagnostic measure, see Robins, 1985). As many of our interviews were conducted by clinicians, the overall validity should be as high as that of other current methods.

Responses to relevant items were scored as absent, subclinically present, or clinically present. These trichotomized scores were used for the correlational analyses to be reported, but only symptoms rated as clinically present were used in creating the $D S M-I I I$ diagnoses. Nonhierarchical lifetime diagnoses were computer generated using $D S M-I I I$ criteria; thus, patients were considered to have obsessive-compulsive disorder if they met the appropriate inclusion criteria, regardless of whether they also met the criteria for another syndrome, such as major depression. (See Boyd et al., 1984, and Leckman, Merikangas, Pauls, Pr usoff, \& Weissman, 1983, for discussions of the validity of exclusion criteria.)
We will consider the relation between the NA and PA scales and anxiety and depression byusing five DSM-III diagnostic groups and their associated symptoms (numbers in parentheses indicate the number of patients receiving each diagnosis): major depression $(n=77)$ and dysthymic disorder $(n=33$ ) represent the depressive spectrum, whereas simple phobia $(n=52)$, social phobia $(n=21)$, obsessive-compulsive disorder $(n=30)$, panic disorder $(n=9)$ and agoraphobia $(n=3)$ comprise the anxiety spectrum. The latter two diagnoses are not considered separately because of their low frequency in this sample. Finally, neither generalized anxiety disorder nor posttraumatic stress disorder are included because they cannot be scored from Version 3.0 of the DIS.

Altogether, $31(21 \%)$ of the subjects received a single DIS diagnosis, $68(45 \%)$ met the criteria for more than one DIS diagnosis, and 51 (34\%) did not receive any DIS diagnosis (the majority of these had a staff consensus diagnosis of substance abuse or personality disorder). Consistent with other patient samples reported in the literature, slightly over half $(57 \%)$ of the 99 subjects who met criteria for at least one DIS diagnosis had both a depressive and an anxiety diagnosis, $19 \%$ had only a depressive disorder, and $24 \%$ met criteria only for anxiety disorder. In analyzing these data, patients are included in a diagnostic group if they meet criteria for that disorder regardless of any other diagnoses they may have. We consider the effect of overlapping diagnoses elsewhere (Clark, in press; Clark \& Watson, in press).

\section{Results}

\section{Symptom-Level Analyses}

Correlations between NEM and PEM and the anxiety symptoms are presented in Table 1; corresponding correlations with the depressive complaints are given in Table 2 . In addition to analyzing the individual items, we created four indexes of problem severity by calculating the number of clinically present complaints in each symptom class. The Ms and SDs for these indexes were: Panic symptoms, $M=1.4, S D=2.6$; phobias, $M=1.7, S D=1.9$; obsessive-compulsive symptoms, $M=.43$, $S D=.75$; depressive symptoms, $M=6.5, S D=4.7$. Correlations between these severity indexes and NEM and PEM are also displayed in Tables 1 and 2. Because of the number of correlations involved, for these analyses only we will use a stringent $p<.01$ cutoff in discussing the statistical significance of the coefficients (although correlations significant at the $p<.05$ level are also noted in the Tables). Also included in these tables are the numbers of patients reporting clinical and subclinical levels of each symptom.

We predicted that NA would be significantly related to both anxiety and depression, but that PA would be correlated only with the latter. The symptom correlations generally support these predictions. Looking first at NA, Tables 1 and 2 demonstrate that NEM is related to a very broad array of complaints, and is significantly associated with most symptoms of both anxiety and depression. Specifically, it is significantly related to 18 of the 33 anxiety complaints (55\%; median $r=.22$ ); within the anxiety disorders, NEM is most strongly related to symptoms of panic, with $86 \%$ of these coefficients reaching significance (median $r=.28$ ). The NEM scale also correlates significantly with 19 of the 20 depressive symptoms (95\%; median $r=.33$ ). Many of the correlations, moreover, are as high as can reasonably be expected (i.e., in the .30 to .50 range), given the unreliability of single items. NEM is also significantly related to all four severity indexes, with the correlations ranging from .25 
Table 1

Correlations Between Negative and Positive Emotionality (NEM and PEM) Scales and Anxiety Symptoms

\begin{tabular}{|c|c|c|c|c|}
\hline \multirow[b]{2}{*}{ Symptom } & \multicolumn{2}{|c|}{$\begin{array}{l}\text { No. of patients } \\
\text { reporting symptom }\end{array}$} & \multicolumn{2}{|c|}{$\begin{array}{c}\text { Correlations } \\
\text { with }\end{array}$} \\
\hline & Clinical & Subclinical & NEM & PEM \\
\hline
\end{tabular}

Symptoms of panic disorder

\begin{tabular}{|c|c|c|c|c|}
\hline Nervousness & 73 & 1 & $.29^{* * *}$ & $-.25 * *$ \\
\hline Panic attacks & 37 & 7 & $.39^{* * *}$ & -.15 \\
\hline \multicolumn{5}{|l|}{ Panic-associated symptoms } \\
\hline Shortness of breath & 21 & 0 & $.27^{* *}$ & -.08 \\
\hline Heart pounding & 34 & 1 & $.34^{* *}$ & -.09 \\
\hline Felt dizzy or light-headed & 18 & 0 & $.30^{* *}$ & -.13 \\
\hline Tingling in fingers or feet & 10 & 1 & $.24^{* *}$ & .00 \\
\hline Tightness or pain in chest & 15 & 1 & $.22^{* *}$ & $-.16^{*}$ \\
\hline Choking or smothering & 14 & 0 & .16 & -.11 \\
\hline Felt faint & 8 & 1 & .14 & .03 \\
\hline Sweating & 27 & 0 & $.28 * *$ & $-.19^{*}$ \\
\hline Trembling/shakiness & 30 & 0 & $.30^{* *}$ & $-.20^{*}$ \\
\hline Hot or cold flashes & 25 & 0 & $.34 * *$ & $-.18^{*}$ \\
\hline $\begin{array}{l}\text { Things seemed unreal } \\
\text { Feared dying or acting }\end{array}$ & 18 & 0 & $.28 * *$ & -.08 \\
\hline crazy & 17 & 0 & $.24^{* *}$ & -.08 \\
\hline $\begin{array}{l}\text { No. of panic } \\
\text { symptoms }\end{array}$ & & & $.36^{* *}$ & -.15 \\
\hline \multicolumn{5}{|c|}{ Phobias } \\
\hline Being in a crowd & 13 & 20 & $.29 * *$ & $-.22 * *$ \\
\hline Eating in public & 7 & 10 & $.17 *$ & $-.19^{*}$ \\
\hline Speaking in public & 11 & 28 & $.17^{*}$ & $-.20^{*}$ \\
\hline Speaking to strangers & 14 & 23 & $.20^{*}$ & $-.22^{* *}$ \\
\hline $\begin{array}{l}\text { Going out of the house } \\
\text { alone }\end{array}$ & 4 & 6 & .14 & $-.17^{*}$ \\
\hline $\begin{array}{l}\text { Being on transportation } \\
\text { vehicles }\end{array}$ & 8 & 18 & $.29 * *$ & -.03 \\
\hline Being alone & 6 & 12 & $.22 * *$ & -.06 \\
\hline Being in a closed place & 14 & 14 & $.17 *$ & -.07 \\
\hline Tunnels or bridges & 3 & 15 & $.19^{*}$ & .04 \\
\hline Storms & 10 & 14 & $.20^{*}$ & -.05 \\
\hline $\begin{array}{l}\text { Spiders, bugs, mice, snakes, } \\
\text { or bats }\end{array}$ & 20 & 34 & $.26^{* *}$ & -.04 \\
\hline $\begin{array}{c}\text { Being near a harmless } \\
\text { animal }\end{array}$ & & & & -05 \\
\hline $\begin{array}{l}\text { animal } \\
\text { Heights }\end{array}$ & $\begin{array}{r}7 \\
19\end{array}$ & $\begin{array}{r}3 \\
33\end{array}$ & $\begin{array}{l}.12 \\
.14\end{array}$ & $\begin{array}{r}-.05 \\
.01\end{array}$ \\
\hline Being in water & 10 & 11 & .02 & -.04 \\
\hline No. of phobias & & & $.25^{* *}$ & -.11 \\
\hline
\end{tabular}

Obsessive-compulsive symptoms

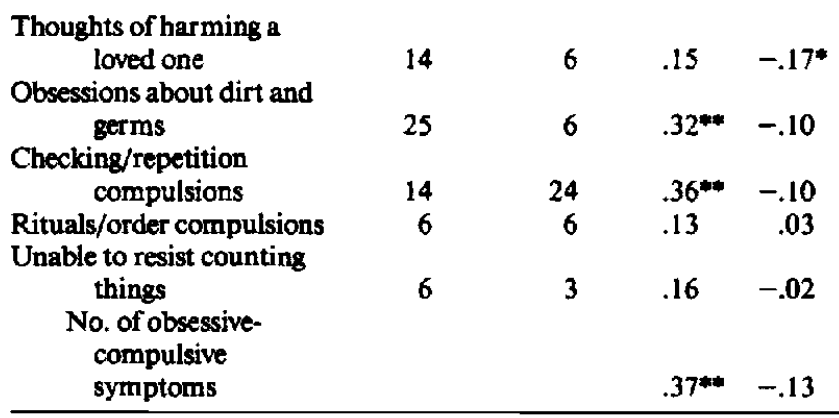

$* p<.05 . * *<.01$. (phobias) to .57 (depression). Clearly, NA represents a very general dimension of subjective distress that subsumes both anxious and depressive complaints; thus, these sections of the DIS-like other psychometric instruments of anxiety and depression-are strongly correlated with this broad and pervasive personality factor (Watson \& Clark, 1984).

Turning now to PA, Tables 1 and 2 indicate that, as expected, PEM is much more strongly and consistently related to depression than anxiety. The PEM scale is significantly related to only 3 of the 33 anxiety symptoms ( $9 \%$; median $r=-.10$ ), and the highest coefficient is only -.25 (with nervousness). Moreover, it is unrelated to all three anxiety severity indexes. In contrast, PEM is significantly associated with 11 of the 20 depression symptoms ( $55 \%$; median $r=-.25$ ), and correlates -.40 with the total number of depressive complaints. An inspection of the individual item coefficients indicates that PEM is especially related to anhedonia and depressed affect, suicidal ideation, feelings of hopelessness and worthlessness, and insomnia/fatigue.

\section{Diagnostic Analyses}

Correlations between NEM and PEM and the DIS-derived diagnoses are shown in Table 3. Consistent with the symptom data, NA is related to both the anxiety and depressive disorders, whereas PA is consistently related only to the latter. The NEM scale is, in fact, significantly related to every diagnosis, with coefficients ranging from .16 with simple phobia to .50 with major depression. The PEM scale is also significantly correlated with both major depression and dysthymic disorder, however, among the anxiety disorders it is related only to social phobia.

The finding that PEM is related to social phobia, though not specifically predicted, is quite congruent with other evidence regarding this mood factor. The PA factor (but not NA) has consistently been found to be significantly correlated with diverse indexes of social behavior, including frequency of contact and satisfaction with friends and relatives, making new acquaintances, involvement in social organizations, and trait measures of sociability or extraversion (Clark \& Watson, 1986, 1988; Costa \& McCrae, 1980; Watson, 1988). Thus, it is not surprising that this particular anxiety disorder-which reflects fear and distress in settings of interpersonal scrutiny-is related to PA as well as NA.

Finally, to assess the combined contributions of NA and PA to the prediction of these disorders, we performed stepwise multiple regression analyses (with forward inclusion) using NEM and PEM as predictors. These analyses were restricted to the three diagnoses (major depression, dysthymic disorder, and social phobia) that were significantly correlated with both scales. The results are presented in Table 4.

Perhaps the most important result emerging from these analyses is the demonstration that NEM and PEM each contribute to the prediction of the depressive disorders. In the case of major depression, the two predictors together account for $31 \%$ of the criterion variance, with PEM contributing an additional $6 \%$ over that possible from NEM alone. Similarly, NEM and PEM account for $22 \%$ of the variance in dysthymic disorder, with the latter again contributing an additional 6\%. Interestingly, however, NEM did not add significantly to the prediction of social phobia, despite the fact that it had a significant zero-order cor- 
Table 2

Correlations Between Negative and Positive Emotionality (NEM and PEM) Scales and Depressive Symptoms

\begin{tabular}{|c|c|c|c|c|}
\hline \multirow[b]{2}{*}{ Symptom } & \multicolumn{2}{|c|}{$\begin{array}{l}\text { No. of patients } \\
\text { reporting symptom }\end{array}$} & \multicolumn{2}{|c|}{$\begin{array}{l}\text { Correlations } \\
\text { with }\end{array}$} \\
\hline & Clinical & Subclinical & NEM & PEM \\
\hline \multicolumn{4}{|l|}{$\begin{array}{l}\text { Felt sad, blue, depressed, } \\
\text { or lost all interest } \\
\text { in things }\end{array}$} & $-.31^{* *}$ \\
\hline $\begin{array}{l}\text { two years } \\
\text { Felt worthless, sinful, }\end{array}$ & 36 & 6 & $.41^{* *}$ & $-.38^{* *}$ \\
\hline guilty & 76 & 1 & $.46^{* *}$ & $-.31^{* *}$ \\
\hline Felt that life was hopeless & 72 & 1 & $.27^{* *}$ & $-.24^{k *}$ \\
\hline Crying spells & 55 & 2 & $.32^{* *}$ & $-.19^{*}$ \\
\hline Thought a lot about death & 69 & 1 & $.41^{* *}$ & $-.33^{* * *}$ \\
\hline $\begin{array}{l}\text { Wanted to die } \\
\text { Thought of committing }\end{array}$ & 54 & 1 & $.22^{* *}$ & $-.33^{* *}$ \\
\hline suicide & 60 & 1 & $.30^{* *}$ & $-.30^{* *}$ \\
\hline Attempted suicide & 33 & 0 & .12 & -.11 \\
\hline Felt tired all the time & 65 & 21 & $.50^{* *}$ & $-.27^{* *}$ \\
\hline Insomnia & 79 & 5 & $.40^{* *}$ & $-.35 * *$ \\
\hline Hypersomnia & 36 & 12 & $.25^{* *}$ & $-.27^{* *}$ \\
\hline $\begin{array}{l}\text { Restlessness/inability to } \\
\text { sit still }\end{array}$ & & & & \\
\hline sit still & 46 & 7 & $.37^{* *}$ & -.12 \\
\hline Psychomotor retardation & 31 & 12 & $.40^{* *}$ & $-.18^{*}$ \\
\hline Slowed thinking & 47 & 10 & $.41^{* *}$ & $-.18^{*}$ \\
\hline Inability to concentrate & 62 & 7 & $.32^{* *}$ & $-.25^{* *}$ \\
\hline Loss of sexual interest & 44 & 13 & $.34^{* *}$ & -.16 \\
\hline Loss of appetite & 62 & 11 & $.32^{* *}$ & $-.17^{*}$ \\
\hline Weight loss & 51 & 11 & $.31^{* *}$ & -.07 \\
\hline Weight gain & 40 & 10 & $.22^{* *}$ & -.05 \\
\hline symptoms & & & $.57^{* *}$ & $-.40^{* *}$ \\
\hline
\end{tabular}

$* p<.05 . * *<<.01$.

relation with this diagnosis (see Table 3). This finding reflects the significant relation $(r=-.37)$ between NEM and PEM in our patient sample; once PEM's influence is partialed out, NEM is no longer significantly correlated with social phobia (partial $r=.12$ ).

\section{Discussion}

The results generally support our predictions, and are consistent with previous research in this area. The data regarding NA are congruent with its conceptualization as a general dimension of psychological distress: NA was consistently correlated with a broad range of anxious and depressive symptoms and diagnoses. In contrast, PA was consistently related only to depressive symptoms and diagnoses, suggesting that the loss of pleasurable engagement (low PA) may be a critical factor in distinguishing depression from anxiety.

One might argue that these results simply reflect content overlap between the PA/NA scales and the psychiatric data. The NA construct, as we have defined it (see also Watson \& Clark, 1984), is clearly a concept that is closely related to anxiety (and, by extrapolation, to the $D S M-I I I$ anxiety disorders). For example, both involve component states of nervousness, apprehension, and fearfulness. Similarly, depression, as it is set forth in
Table 3

Correlations Between Negative and Positive Emotionality (NEM and PEM) Scales and Diagnostic Interview Schedule Diagnoses of the Anxiety and Depressive Disorders

\begin{tabular}{lll}
\hline & \multicolumn{2}{c}{ Correlations with } \\
\cline { 2 - 3 } \multicolumn{1}{c}{ Diagnosis } & NEM & PEM \\
\hline Anxiety disorders & & \\
Obsessive-compulsive disorder & $.39^{* *}$ & -.12 \\
Simple phobia & $.16^{*}$ & -.01 \\
Social phobia & $.20^{*}$ & $-.23^{*}$ \\
Any anxiety diagnosis & $.32^{* *}$ & -.12 \\
Depressive disorders & & \\
Major depression & $.50^{* *}$ & $-.41^{* *}$ \\
Dysthymic disorder & $.39^{* *}$ & $-.37^{* *}$ \\
Any depressive diagnosis & $.51^{* *}$ & $-.38^{* *}$ \\
\hline
\end{tabular}

Note. All diagnoses are scored dichotomously $(0=a b s e n t, 1=$ present $)$. ${ }^{*} p<.05{ }^{* *} p<.01$.

$D S M-I I I$, may be interpreted as a disorder involving both high NA (dysphoria) and low PA (loss of pleasure). Moreover, one can point to specific NEM and PEM items that overlap with various diagnostic criteria. For example, the NEM item (paraphrased) "I often have trouble sleeping because of my worries" is conceptually related to the "insomnia" criterion for major depressive disorder, whereas the PEM item (paraphrased) "On most days I have some feelings of real joy" seems to be an opposite expression of the DSM-III criterion of prominent and persistent depressed mood.

However, NEM and PEM are also correlated with many individual symptoms (and their respective diagnoses) that do not involve any overlapping content. For example, almost all of the symptoms of panic disorder-which mostly involve physiological manifestations of extreme anxiety- were significantly correlated with NEM, even though none of the NEM items refer to somatic complaints. (These results are consistent with other research showing that NEM is significantly related to a broad range of physical symptoms; Watson \& Pennebaker, in press.)

Table 4

Regressions of Negative and Positive Emotionality (NEM and PEM) Scales on Major Depression. Dysthymic

Disorder, and Social Phobia

\begin{tabular}{lcccc}
\hline \multicolumn{1}{c}{ Criterion } & Predictor & $B^{\mathbf{a}}$ & $R$ & $R^{2}$ Change \\
\hline Major depression & & & & \\
$\quad$ Step 1 & NEM & $.40^{* *}$ & .50 & $.25^{* *}$ \\
Step 2 & PEM & $-.26^{* *}$ & .55 & $.06^{* *}$ \\
Dysthymic disorder & & & & \\
Step 1 & NEM & $.30^{* *}$ & .39 & $.16^{* *}$ \\
$\quad$ Step 2 & PEM & $-.26^{* *}$ & .46 & $.06^{* *}$ \\
Social phobia & & & & \\
Step 1 & PEM & $-.19^{*}$ & .23 & $.06^{* *}$ \\
Step 2 & NEM & .13 & .26 & .01 \\
\hline
\end{tabular}

- Standardized regression coefficient.

$* p<.05 * 0<.01$. 
Similarly, NEM contains no items specifically referring to phobias, and yet it was significantly correlated with most of the DIS phobic items.

As for the depressive symptoms, neither the NEM nor PEM items refer directly to fatigue, suicidal tendencies, appetite disturbance, or difficulty concentrating, and yet these symptoms are significantly correlated with scores on both scales. Thus, while a few of the individual correlations may reflect content overlap, such considerations alone cannot explain the overall pattern of results.

\section{The Role of NA and PA in Anxiety and Depression}

As expected, NA was broadly correlated with symptoms and diagnoses of both anxiety and depression, confirming earlier findings that it is an important general correlate of psychiatric disorder (Watson \& Clark, 1984). By the same token, however, the pervasiveness of its relation to psychiatric complaints suggests that NA will not prove very useful in differential diagnosis. That is, NA is a diffuse index of psychological distress that can be expected to differentiate most patient groups from normals, but that will not effectively distinguish specific types of psychiatric disorder from one another. Thus, the substantial overlap between anxiety and depression described earlier may derive from the fact that they share NA as a common underlying construct. In this view, a major component of both depression and anxiety is a fundamental predisposition to experience a wide variety of negative emotional states, and correlations between measures of depression and anxiety may largely reflect the fact that both assess specific facets of NA.

The PA factor, in contrast, was related primarily to symptoms and diagnoses of depression. Although PA's contribution to the prediction of the depressive diagnoses was smaller than that of $\mathrm{NA}$, at the symptom level, NA and PA were comparably related to depression (median $r=.33$ and -.25 , respectively). These and other data thus indicate that the differential measurement of depression might be improved if the PA component were weighted more heavily. Currently, most self-report depression scales largely tap NA, but also include a more modest PA component (see Tellegen, 1985; Watson \& Clark, 1984; Watson, Clark, \& Tellegen, 1988). In terms of convergent validity, this is a good strategy because depression appears to be an affectively complex combination of high NA and low PA. However, this high NA component is also prominent in anxiety, and so will produce high correlations among depression and anxiety measures. Because low PA is a more important factor in depression than anxiety, strengthening this component in depression measures should improve their discrimination from anxiety scales.

One important consideration is how best to assess this PA component. Psychiatric research has traditionally emphasized dichotomous measurement: A given symptom such as anhedonia is recorded as present or absent. However, extensive recent evidence indicates that PA is a normally distributed dimension of both inter- and intraindividual differences (e.g., Clark \& Watson, 1988; Costa \& McCrae, 1980; Watson, 1988; Watson et al., 1988 ; Watson \& Tellegen, 1985). That is, people differ greatly in their characteristic PA levels, and a given individual's PA fluctuates widely from day to day and from moment to moment. Rather than simply assessing the presence/absence of positive emotional experiences, it seems desirable to adopt a measurement strategy that allows these finer gradations to be identified and studied. In particular, the dimensional approach seems better suited to the study of factors (both biological and environmental) that influence positive emotionality.

It might also be useful to focus more on the measurement of high PA. Our experience in mood assessment indicates that there are many more descriptors of high than low PA and, furthermore, that the high PA terms tend to be purer markers of the underlying factor (e.g., Watson et al., 1988; Watson \& Tellegen, 1985). Thus, the best measurement approach may be to assess the degree to which respondents report various high PA experiences. Depressive symptoms can then be inferred from the relative absence of any such experiences.

Finally, we should also note some limitations of our study. First, although the results are very orderly and generally supportive of our model, it is clearly important that they be replicated. Moreover, as noted earlier, the form of the DIS used in this study (Version 3.0) did not permit the assessment of either generalized anxiety disorder or posttraumatic stress disorder. Given their current conceptualization, we suspect that these disorders will be strongly related to trait NA, but this obviously requires empirical confirmation. Thus, it is important that subsequent studies examine the full range of anxiety disorders.

It would also be interesting to examine how anxiety and depression relate to different types of trait NA and trait PA measures. For example, as was discussed previously, PEM and NEM are moderately correlated. This poses no theoretical problem (because the underlying factors themselves may be modestly correlated), but the resulting lack of statistical independence does create some interpretive problems for the multiple regression analyses involving the depressive diagnoses (see Table 4). Because NEM and PEM are correlated, and because NEM was entered into the regression equations first (so that its influence is partialed out), these analyses may underestimate PA's true contribution to the prediction of depression. However, this is impossible to determine without further data. We are in the process of validating a new, longer (22-item) trait PA scale that was designed to be more clearly independent of trait NA; it will be interesting to examine how this scale relates to the depressive disorders.

In summary, the findings of the present study indicate that the shared element of NA may underlie the consistently strong correlation between measures of anxiety and depression; however, the data also demonstrate that PA is more specifically related to depression. On the basis of the data we have presented, we believe that researchers of anxiety and depression would profit from an improved understanding of the extensive literature on the nature and correlates of NA and PA. Conversely, research into the causes and treatment of anxiety and depression will likely enhance our understanding of the basic mechanisms underlying the experience of NA and PA. At the very least, we hope that this article will stimulate an increased level of interaction between these research traditions.

\section{References}

Akiskal, H. S. (1985). Anxiety: Definition, relationship to depression, and proposal for an integrative model. In A. H. Tuma \& J. D. Maser 
(Eds.), Anxiety and the anxiety disorders (pp, 787-797). Hillsdale, NJ: Erlbaum.

American Psychiatric Association. (1980). Diagnostic and statistical manual of mental disorders (3rd ed.). Washington, DC: Author.

Anthony, J. C., Folstein, M., Romanoski, A. J., Von Korff, M. R., Nestadt, G. R., Chahal, R., Merchant, A., Brown, C. H., Shapiro, S., Kramer, M., \& Gruenberg, E. M. (1985). Comparison of the lay Diagnostic Interview Schedule and a standardized psychiatric diagnosis. Archives of General Psychiatry, 42, 667-675.

Blumberg, S. H., \& Izard, C. E. (1986). Discriminating patterns of emotions in 10- and 11 -year-old children's anxiety and depression. Journal of Personality and Social Psychology, 51, 852-857.

Bouman, T. K., \& Luteijn, F. (1986). Relations between the Pleasant Events Schedule, depression, and other aspects of psychopathology. Journal of Abnormal Psychology, 95, 373-377.

Boyd, J. H., Burke, J. D., Jr., Gruenberg, E., Holzer, C. E. Ill, Rae, D. S., George, L. K., Karno, M., Stoltzman, R., McEvoy, L., \& Nestadt, G. (1984). Exclusion criteria of DSM-IIl : A study of co-occurrence of hierarchy-free syndromes. Archives of General Psychiatry, 41, 983989.

Breier, A., Charney, D. S., \& Heninger, G. R. (1985). The diagnostic validity of anxiety disorders and their relationship to depressive illness. American Jourmal of Psychiatry, 142, 787-797.

Breier, A., Charney, D. S., \& Heninger, G. R. (1986). Agoraphobia with panic attacks: Development, diagnostic stability, and cause of illness. Archives of General Psychiatry, 43, 1029-1036.

Clark, L. A. (in press). The anxiety and depressive disorders: Descriptive psychopathology and differential diagnosis. In P. C. Kendall \& D. Watson (Eds.). Anxiety and depression: Distinctive and overlapping features. New York: Academic Press.

Clark, L. A., \& Watson, D. (1986, August). Diurnal variation in mood: Interaction with daily events and personality. Paper presented at the 94th Annual Convention of the American Psychological Association, Washington, DC.

Clark, L. A., \& Watson, D. (1988). Mood and the mundane: Relations between daily life events and self-reported mood. Journal of Personality and Sacial Psychology, 54, 294-306.

Clark, L. A., \& Watson, D. (in press). Theoretical and empirical issues in differentiating depression from anxiety. In J. Becker \& A. Kleinman (Eds.), Advances in mood disorders: Vol. I. Psychological aspects. New York: Erlbaum.

Costa, P. T., Jr., \& McCrae, R. R. (1980). Influence of extraversion and neuroticism on subjective well-being: Happy and unhappy people. Joumal of Personality and Social Psychology, 38, 668-678.

Deluty, B. M., Deluty, R. H., \& Carver, C. S. (1986). Concordance between clinicians' and patients' ratings of anxiety and depression as mediated by private self-consciousness. Journal of Personality Assessment, 50, 93-106.

Derogatis, L. R., Klerman, G. L., \& Lipman, R. S. (1972). Anxiety states and depressive neuroses. Journal of Nervous and Mental Disease, 55, 392-403.

Dobson, K. S. (1985). An analysis of anxiety and depression scales. Journal of Personality Assessment, 49, 522-527.

Eysenck, H. (1970). The structure of human personality. London: Methuen.

Foa, E. B., \& Foa, U. G. (1982). Differentiating depression and anxiety: Is it possible? Is it useful? Psychopharmacology Bulletin. 18, 62-68.

Foa, E. B., Grayson, J. B., Steketee, G. S., Doppelt, H. G., Turner, R. M., $\&$ Latimer, P. R. (1983). Success and failure in the behavioral treatment of obsessive-compulsives. Joumal of Consulting and Clinical Psychology, 51, 287-297.

Gersh, F. S., \& Fowles, D. C. (1979). Neurotic depression: The concept of anxious depression. In R. A. Depue (Ed.), The psychobiology of the depressive disorders: Implications for the effects of stress (pp. 81104). New York: Academic Press.

Gotlib, I. H. (1984). Depression and general psychopathology in university students. Joumal of Abnormal Psychology, 93, 19-30.

Hall, C. A. (1977). Differential relationships of pleasure and distress with depression and anxiety over a past, present and future time framework. Unpublished doctoral dissertation, University of Minnesota.

Helzer, J. E., Robins, L. N., McEvoy, L. T., Spitznagel, E. L., Stoltzman, R. K., Farmer, A., \& Brockington, I. F. (1985). A comparison of clini$\mathrm{cal}$ and Diagnostic Interview Schedule diagnoses. Archives of General Psychiatry, 42, 657-666.

Hesselbrock, V., Stabenau, J., Hesselbrock, M., Mirkin, P., \& Meyer, R. (1982). A comparison of two interview schedules. Archives of General Psychiatry, 39, 674-677.

Kupfer, D. J., Spiker, D. G., Rossi, A., Coble, P. A., Ulrich, R., \& Shaw, D. (1983). Recent diagnostic and treatment advances in REM sleep and depression. In P. J. Clayton \& J. E. Barrett (Eds.), Treatment of depression: Old controversies and new approaches (pp. 31-51). New York: Raven Press.

Leckman, J. F., Merikangas, K. R., Pauls, D. L., Prusoff, B. A., \& Weissman, M. M. (1983). Anxiety disorders and depression: Contradictions between family study data and DSM-III conventions. American Journal of Psychiatry, 140, 880-882.

Lipman, R. S., Rickels, K., Covi, L., Derogatis, L. R., \& Uhlenhuth, E. H. (1969). Factors of symptom distress: Doctor ratings of anxious neurotic outpatients. Archives of General Psychiatry, 21, 328-338.

Mendels, J., Weinstein, N., \& Cochrane, C. (1972). The relationship between depression and anxiety. Archives of General Psychiatry, 27, 649-653.

Nezu, A. M., Nezu, C. M., \& Nezu, V. A. (1986). Depression, general distress, and causal attributions among university students. Joumal of Abnormal Psychology, 95, 184-186.

Orme, J. G., Reis, J., \& Herz, E. J. (1986). Factorial and discriminant validity of the Center for Epidemiological Studies Depression (CESD) Scale. Journal of Clinical Psychology, 42, 28-33.

Robins, L. N. (1985). Epidemiology: Reflections on testing the validity of psychiatric interviews. Archives of General Psychiatry, 42, 918924.

Robins, L. N., Helzer, J. E., Croughan, I., \& Ratcliff, K. S. (1981). The NIMH Diagnostic Interview Schedule: Its history, characteristics, and validity. Archives of General Psychiatry, 38, 381-389.

Roth, M., Gurney, C., Garside, R. F., \& Kerr, T. A. (1972). Studies in the classification of affective disorders-the relationship between anxiety states and depressive illnesses. British Journal of Psychiatry, 121, 147-161.

Tanaka-Matsumi, J., \& Kameoka, V. A. (1986). Reliabilities and concurrent validities of popular self-report measures of depression, anxiety, and social desirability. Journal of Consulting and Clinical Psychology, 54, 328-333.

Tellegen, A. (1982). Brief manual for the Differential Personality Questionnaire. Unpublished manuscript, University of Minnesota, Minneapolis.

Tellegen, A. (1985). Structures of mood and personality and their relevance to assessing anxiety, with an emphasis on self-report. In A. H. Tuma \& J. D. Maser (Eds.), Anxiety and the anxiety disorders (pp. 681-706). Hillsdale, NJ: Erlbaum.

Tellegen, A. (in press). Multidimensional Personality Questionnaire. Minneapolis, MN: University of Minnesota Press.

Watson, D. (1988). Intraindividual and interindividual analyses of positive and negative affect: Their relation to health complaints, perceived stress, and daily activities. Journal of Personality and Social Psychology, 54, 1020-1030.

Watson, D., \& Clark, L. A. (1984). Negative affectivity: The disposition 
to experience aversive emotional states. Psychological Bulletin, 96, $465-490$.

Watson, D., Clark, L. A., \& Tellegen, A. (1984). Cross-cultural convergence in the structure of mood: A Japanese replication and a comparison with U.S. findings. Journal of Personality and Social Psychology, 47, 127-144.

Watson, D., Clark, L. A., \& Tellegen, A. (1988). Development and validation of brief measures of Positive and Negative Affect: The PANAS Scales. Journal of Personality and Social Psychology, 54, 1063-1070.

Watson, D., \& Pennebaker, J. W. (1988). [Personality, health, and emotional characteristics of a university employee sample.] Unpublished raw data.

Watson, D., \& Pennebaker, J. W. (in press). Health complaints, stress, and distress: Exploring the central role of negative affectivity. Psychological Review.

Watson, D., \& Tellegen, A. (1985). Toward a consensual structure of mood. Psychological Bulletin, 98, 219-235.

Wittchen, H.-U., Semler, G., \& von Zerssen, D. (1985). A comparison of two diagnostic methods: Clinical ICD diagnoses versus DSM-III and Research Diagnostic Criteria using the Diagnostic Interview Schedule (Version 2). Archives of General Psychiatry, 42, 677-684.

Wolfe, V. V., Finch, A. J., Jr., Saylor, C. F., Blount, R. L., Pallmeyer, T. P., \& Carek, D. J. (1987). Negative affectivity in children: A multitraitmultimethod investigation. Journal of Consulting and Clinical Psychology, 55, 245-250.

Woodruff, R. A., Jr., Guze, S. B., \& Clayton, P. J. (1972). Anxiety neurosis among psychiatric outpatients. Comprehensive Psychiatry, 13, $165-170$.

Zuckerman, M., Persky, H., Eckman, K., \& Hopkins, T. (1967). A multitrait multimethod measurement approach to the traits (or states) of anxiety, depression, and hostility. Journal of Projective Techniques and Personality Assessment, 31, 39-48.

Zurawski, R. M., \& Smith, T. W. (1987). Assessing irrational beliefs and emotional distress: Evidence and implications of limited discriminant validity. Journal of Counseling Psychology, 34, 224-227.

Received August 3, 1987

Revision received February 4, 1988

Accepted February 9, 1988

\section{Members of Underrepresented Groups: \\ Reviewers for Journal Manuscripts Wanted}

If you are interested in reviewing manuscripts for APA journals, the APA Publications and Communications Board would like to invite your participation. Manuscript reviewers are vital to the publication process. As a reviewer, you would gain valuable experience in publishing. The $\mathrm{P} \& \mathrm{C}$ Board is particularly interested in encouraging members of underrepresented groups to participate more in this process.

If you are interested in reviewing manuscripts, please write to Leslie Cameron at the address below. Please note the following important points:

- To be selected as a reviewer, you must have published articles in peer-reviewed journals. The experience of publication provides a reviewer with the basis for preparing a thorough, objective evaluative review.

- To select the appropriate reviewers for each manuscript, the editor needs detailed information. Please include with your letter your vita. In your letter, please identify which APA journal you are interested in and describe your area of expertise. Be as specific as possible. For example, "social psychology" is not sufficient-you would need to specify "social cognition" or "attitude change" as well.

- Reviewing a manuscript takes time. If you are selected to review a manuscript, be prepared to invest the necessary time to evaluate the manuscript thoroughly.

Write to Leslie Cameron, Journals Office, APA, 1400 N. Uhle Street, Arlington, Virginia 22201. 